\title{
PRÁTICAS FORMATIVAS INTERDISCIPLINARES: PERTENCIMENTO E PERMANÊNCIA NA EDUCAÇÃO SUPERIOR A DISTÂNCIA
}

\author{
CURITIBA/PR ABRIL/2018
}

\author{
LUÍS FERNANDO LOPES - UNINTER - luis.I@uninter.com \\ Gisele do Rocio Cordeiro - UNINTER - gisele.c@uninter.com \\ Edison Neres Barbosa - UNINTER - edison.b@uninter.com
}

Tipo: Relato de Experiência Inovadora (EI)

Categoria: Métodos e Tecnologias

Setor Educacional: EDUCAÇÃO SUPERIOR

\begin{abstract}
RESUMO
Este artigo, apresentado na forma de relato de experiência, é fruto de um trabalho realizado com os alunos dos Cursos de Licenciatura na modalidade a distância (EAD) no ano de 2017, nos quais ofertouse práticas formativas interdisciplinares. O objetivo geral foi analisar a pertinência da oferta dessas práticas na perspectiva do pertencimento e da permanência em curso superior de Licenciatura na modalidade EAD. Além do referencial teórico adotado, levou-se em conta as determinações dos requisitos legais e normativos, bem como as indicações do instrumento de avaliação para cursos superiores. Os resultados apontam, que a oferta de práticas formativas interdisciplinares em cursos superiores de Licenciatura na modalidade a distância, pelo fato de proporcionarem momentos de vivência e aplicação dos conhecimentos adquiridos, favorecem o desenvolvimento do sentimento de pertencimento no curso colaborando para permanência do estudante no ensino superior com vistas à conclusão do curso.
\end{abstract}

Palavras-chave: Práticas Formativas; Educação a Distância; Cursos de Licenciatura.

AGRADECIMENTOS

AO CENTRO UNIVERSITÁRIO INTERNACIONAL UNINTER E À ESCOLA SUPERIOR DE EDUCAÇÃO PELO APOIO E INCETIVO PARA A REALIZAÇÃO DESSA PESQUISA. 


\section{INTRODUÇÃo}

Este artigo, na forma de relato experiência é fruto de um trabalho realizado com os alunos dos cursos de Licenciatura na modalidade EAD no ano de 2017, nos quais foram ofertadas práticas formativas interdisciplinares, como proposta de extensão. A proposta lançada levou em consideração o Instrumento de Avaliação de Cursos de Graduação, documento que subsidia os atos autorizativos de cursos - autorização, reconhecimento e renovação de reconhecimento, que em um de seus itens aborda as Atividades práticas de ensino para Licenciaturas.

Durante a realização dos cursos de Licenciatura, os estudantes precisam comprovar a participação em atividades acadêmicas científico-culturais, também chamadas de atividades complementares. Nesse sentido, merece destaque a necessidade de nos cursos de formação de docente, assim como no Ensino Superior de maneira geral, aliar teoria e a prática. Nessa perspectiva foi elaborado o projeto para a oferta de práticas formativas interdisciplinares nos cursos de Licenciatura na modalidade a distância, tendo em visa a ampliação do horizonte de formação dos alunos. O objetivo deste artigo foi descrever as práticas formativas interdisciplinares ofertadas e perceber 0 alcance que elas tiveram nos cursos de Licenciatura EAD de uma Instituição de Educação Superior do Sul do país, enquanto elemento potencializador do desenvolvimento profissional docente, que colabora para o desenvolvimento do sentimento de pertença ao curso e à Instituição e consequentemente favorece a permanência do estudante no Ensino Superior.

\section{PRÁTICAS FORMATIVAS: ALGUMAS CONSIDERAÇÕES}

Nakayama (2017) no artigo Práticas Formativas e Desenvolvimento Profissional Docente em grupos que integram ensino, pesquisa e extensão, analisou as articulações realizadas entre o ensino, pesquisa e extensão no âmbito de um projeto de pesquisa em desenvolvimento na Universidade Federal de São Carlos (UFSCar - Campus Sorocaba) para evidenciar os tipos de práticas que potencializam o desenvolvimento profissional docente. Os resultados apontaram para a potencialidade da indissociabilidade entre ensino pesquisa e extensão, enquanto proposta formativa e de produção de conhecimento que contribui para a construção da autoria e autonomia emancipatória no exercício da profissão docente.

Martins, Dias e Martins Filho (2016) por sua vez, realizaram uma pesquisa que teve como objetivo problematizar algumas questões relativas à formação de professores dos cursos de Pedagogia e de Geografia da Faculdade de Educação da Universidade do 
Estado de Santa Catarina tendo como princípio básico a tríade ensino, pesquisa e extensão. Seu estudo apresentou uma discussão teórica que teve como base a pesquisa bibliográfica e uma reflexão sobre as atividades desenvolvidas na promoção de uma formação que estabelece relações entre a universidade e a escola de educação básica.

Para tanto, destaram os projetos de ensino, pesquisa e extensão desenvolvidos nesses dois cursos e que contribuem para desenvolver uma visão crítica da realidade, bem como uma leitura do contexto profissional em que esses professores atuarão. Os resultados da pesquisa mostraram que os diferentes projetos de ensino, pesquisa e extensão, permitem reconstruir novas possibilidades para uma formação docente mais humanizadora. Um curso de formação de professores que tem a relação entre esses três aspectos como um prisma, reconhece que essa formação precisa ocorrer de forma articulada com os futuros espaços profissionais de atuação do egresso.

Nesta perspectiva, a resolução CNE/CP $n^{\circ}$ 2, de 09 de junho de 2015, que define as Diretrizes Curriculares Nacionais para a formação inicial em nível superior (cursos de licenciatura, cursos de formação pedagógica para graduados e cursos de segunda licenciatura) e para a formação continuada, estabelece como um dos princípios da Formação de Profissionais do Magistério da Educação Básica, "a articulação entre a teoria e a prática no processo de formação docente, fundada no domínio dos conhecimentos científicos e didáticos, contemplando a indissociabilidade entre ensino, pesquisa e extensão" (BRASIL, 2015, p. 4).

Já o instrumento de avaliação de cursos Superiores do Ministério da Educação que subsidia os atos autorizativos de cursos - autorização, reconhecimento e renovação de reconhecimento - nos graus de tecnólogo, de licenciatura e de bacharelado para a modalidade presencial e a distância. Para este estudo considerou-se principalmente a dimensão 1 do documento. Tal dimensão aborda a Organização Didático Pedagógica dos cursos de graduação, cujos critérios são avaliados com nota de 1 a 5 . Dentre os critérios de avaliação da dimensão 1, destacou-se o item 1.27 do instrumento que diz respeito às atividades práticas de ensino para Licenciaturas. (BRASIL, 2017).

Nesse sentido, a Resolução CNE/CP № 2, de 09 de junho de 2015, estabelece que os cursos de formação inicial para os profissionais do magistério para a educação básica, em nível superior, compreendem entre outros elementos:

[...] atividades práticas articuladas entre os sistemas de ensino e instituições educativas de modo a propiciar vivências nas diferentes áreas do campo educacional, assegurando aprofundamento e diversificação de estudos, experiências e utilização de recursos pedagógicos; 
Já o Parecer CNE/CP n 28/2001 compreende a prática como um trabalho consciente de apoio do processo formativo, a fim de dar conta dos múltiplos modos de ser da atividade acadêmico-científica. Assim, ela deve ser planejada quando da elaboração do projeto pedagógico e seu acontecer deve se dar desde o início da duração do processo formativo e se estender ao longo de todo o seu processo.

\section{PRÁTICAS FORMATIVAS INTERDISCIPLINARES NA INSTITUIÇÃO PESQUISADA: PRINCÍPIOS NORTEADORES}

A proposta de oferta de Práticas Formativas Interdisciplinares para os cursos de Licenciatura da Instituição pesquisada tem como princípios pedagógicos norteadores: 1) Inovação, 2) flexibilidade, 3) interdisciplinaridade, 4) formação de competências, 6) autonomia de aprendizagem, 7) tecnologias educacionais, 8) andragogia, 9) metodologias ativas e 10) características loco-regionais.

Com relação à inovação, a oferta de práticas formativas interdisciplinares traz essa marca desde a sua concepção. A proposta de oferecer atividades que integram teoria e prática e permitem aos alunos dos cursos de formação de professores na modalidade a distância aprender com a aplicação dos conteúdos estudados apresenta-se como inovação que colabora para o desenvolvimento profissional docente, bem como para desenvolver o sentimento de pertencimento com vistas à permanência do estudante no curso. Quanto à flexibilidade, é outro princípio pedagógico norteador que se faz presente nas práticas formativas ofertadas ao longo dos cursos de Licenciatura na modalidade a distância, na instituição pesquisada. Os estudantes podem participar das atividades ofertadas de maneira síncrona ou assíncrona. As atividades práticas são realizadas com a participação de professores a partir de um estúdio central na sede da instituição e com a participação e realização de atividades nos polos de apoio presencial. Os estudantes também podem realizar essas atividades por meio do ambiente virtual de aprendizagem de acordo com sua disponibilidade de tempo.

Quanto ao terceiro item, a interdisciplinaridade é preciso destacar que as práticas formativas ofertadas na instituição em estudo, já foram concebidas em uma perspectiva interdisciplinar, que, respeitando a singularidade de cada curso pudesse atender aos estudantes dos cursos de licenciatura com atividades práticas, que colaborem para a formação integral do futuro docente. Entre as práticas formativas interdisciplinares ofertadas que ressalta essa perspectiva interdisciplinar pode-se destacar, por exemplo, as seguintes temáticas já trabalhadas: 1) Mapas Conceituais como recurso didático para compreensão de conteúdos; 2) A relação da Música com a Matemática no ensino fundamental; 3) Interpretação e resolução prática de situações-problema no ensino 
fundamental. Já a formação de competências está intimamente ligada com a oferta das práticas formativas interdisciplinares na instituição pesquisada, que permitem ao discente licenciando aplicar o conteúdo estudado e desenvolver competências relativas à sua atuação como futuro professor. Nessa perspectiva, ressalta-se que os estudantes têm a oportunidade de entrar em contato com práticas inovadoras na educação e ao mesmo tempo vivenciá-las de maneira a concretizar o desenvolvimento das competências esperadas.

A autonomia de aprendizagem, por sua vez é uma caraterística que se procura desenvolver em todos os momentos durante a oferta do curso. Assim, a oferta de práticas formativas interdisciplinares procura potencializar o desenvolvimento da autonomia do estudante. A participação nessas práticas, não é obrigatória, contudo, o estudante é incentivado a buscar uma ampliação do seu escopo formativo com vistas à sua atuação profissional e ainda sua formação numa perspectiva integral. As tecnologias educacionais são fundamentais para que o processo de oferta e realização das práticas formativas interdisciplinares se concretize. Destaca-se o fato que o ambiente virtual de aprendizagem foi concebido e preparado para atender às necessidades dos cursos da instituição. Desta forma, realizam-se avaliações e atualizações constantes tendo como foco garantir a oferta de cursos de qualidade aos estudantes e sua participação ativa nos cursos.

Figura 1: Ambiente Virtual de aprendizagem

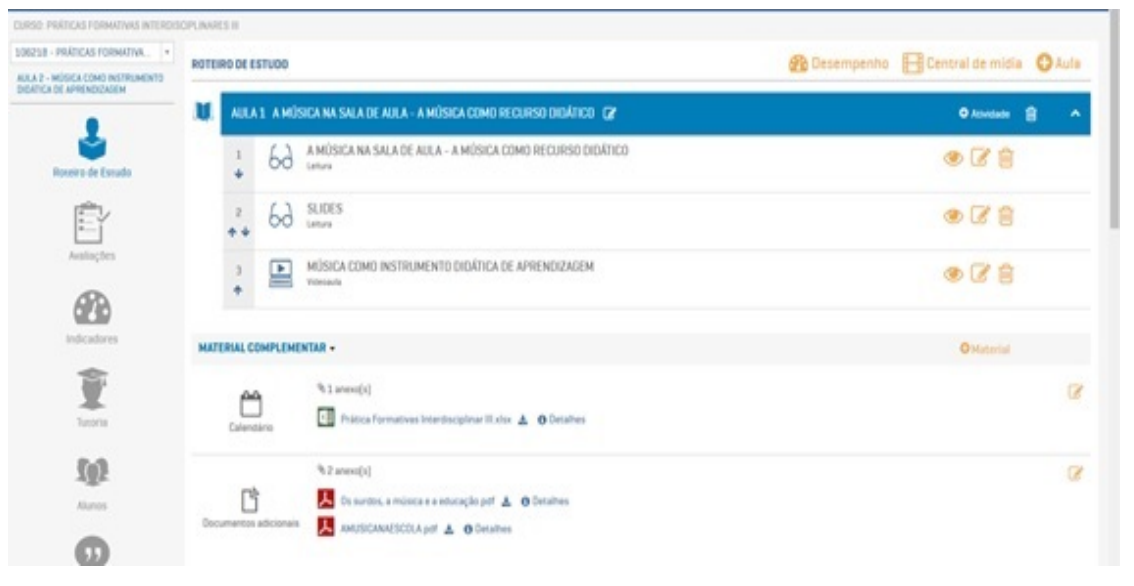

Fonte: Acervo digital da instituição (2017)

A andragogia também é um princípio norteador na oferta das práticas informativas interdisciplinares. $\mathrm{O}$ aluno adulto busca conhecimentos que façam sentido para ele e cuja aplicação possa ser percebida experimentada. Contudo, vale destacar preocupação da instituição pesquisada com o aprendizado da base teórica aliada a prática, de 
maneira a superar a dicotomia teoria e prática, um desafio que está presente no ensino superior de modo geral não apenas nos cursos de formação de professores. Quanto às metodologias ativas, a oferta das práticas formativas interdisciplinares permitem aos estudantes concretizar o aprendizado por meio dessas metodologias, pois, além de contar com professores com longa experiência profissional que apresentam propostas de práticas pedagógicas inovadoras, os estudantes precisam aplicar os conteúdos estudados por meio de atividades práticas realizadas no ambiente virtual de aprendizagem e nos Polos de apoio presencial.

Por fim, no que diz respeito às características loco-regionais as práticas formativas ofertas na instituição em estudo, possibilitam ao estudante uma aplicação que considere as características e necessidades dos locais onde os polos de apoio presencial da instituição estão presentes. Assim, os estudantes têm a oportunidade de realizar práticas que reverberam no espaço social em que estão presentes. Como exemplos de práticas que favorecem essa inserção loco regional já ofertadas pode-se citar a temática da coleta seletiva no contexto das cidades educadoras conforme apresentado na imagem a seguir:

Figura 2 - Prática formativa sobre coleta seletiva no contexto das cidades educadoras

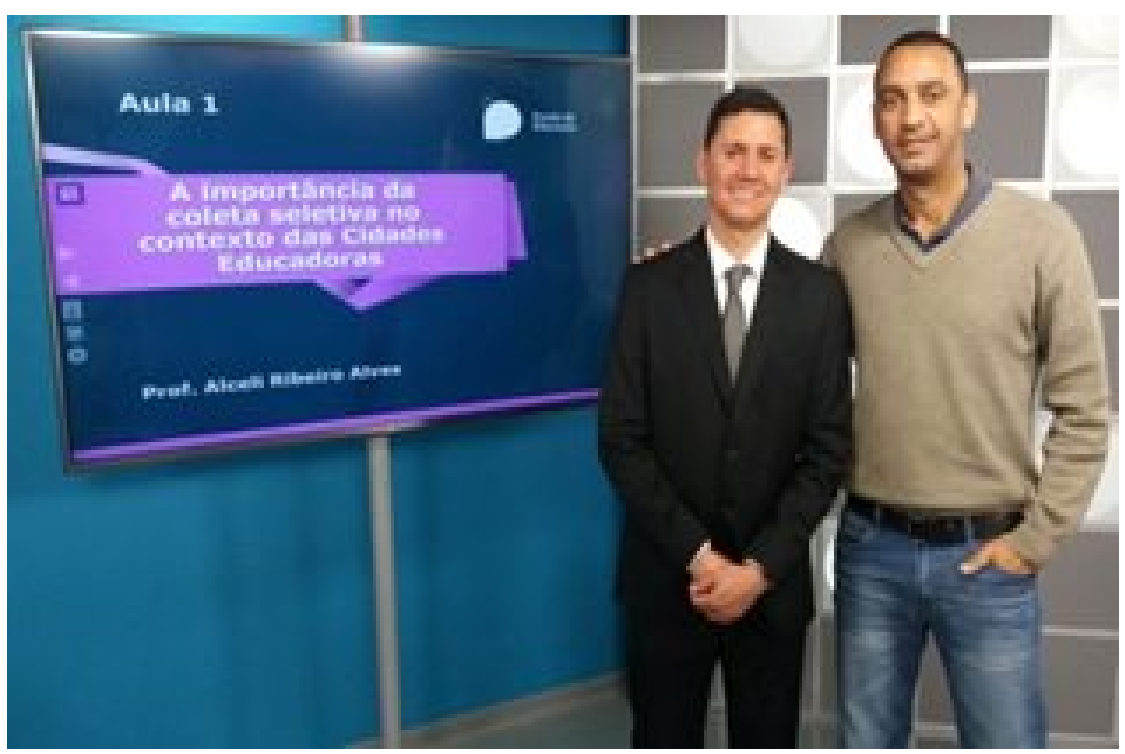

Fonte: Acervo digital da instituição (2017)

Ao longo de 2017 foram ofertadas 51 (cinquenta e uma) práticas formativas interdisciplinares que contaram com a participação de 5.542 (cinco mil e quinhentos e quarenta e dois alunos de 9 (nove) cursos de Licenciatura. Os temas abordados nessas práticas foram: 1) Elaboração do plano de aula; 2) Mapas Conceituais; 3) Os gêneros discursivos na escola: 4) Proposta Interdisciplinar; 5) Educação e Práticas Sustentáveis 
na escola; 6)História e espaço urbano; 7) O uso da tecnologia em sala de aula; 8) Alfabetização cartográfica; 9) Utilização de tecnologias na análise combinatória; 10) História e Gênero; 11) ENEM: como preparar alunos do Ensino Médio (práticas de sala de aula); 12) O uso do material dourado como recurso didático para o ensino das casas decimais; 13) Como fazer a contextualização/interdisciplinaridade; 14) Romances históricos contemporâneos: Um olhar sobre a escravidão feminina nos séculos XVIIIXIX; 15) Mapas Conceituais como recurso didático para compreensão de conteúdos; 16) A relação da Música com a Matemática no ensino fundamental; 17) Interpretação e resolução prática de situações-problema no ensino fundamental; 18) Monoculturalismo, multiculturalismo e relações étnico-raciais na escola; 19) 20) A compreensão, as diferentes interpretações e o significado da palavra diversidade segundo a língua portuguesa; 21) A finalidade do ensino da língua inglesa no fundamental; 22) Combatendo a dengue, chikungunya e zika nas escolas; 23) Estatística Multivariada no cotidiano; 24) Reforma protestante; 25) Matemática como meio para a Interdisciplinaridade; 26) O uso da história da ciência no ensino da matemática; 27) 0 livro de matemática no contexto do PNLD; 28) Romance histórico brasileiro; 29) O lúdico em sala de aula; 30) As tecnologias no ensino de matemática: o uso de documentários no ensino de matemática; 30) Preconceito linguístico: o que todo professor precisa saber?; 31) As tecnologias no ensino de matemática: o uso de celulares no ensino de matemática; 32) Estratégias para o ensino de Ciências; 33) O papel e o registro de situações pedagógicas do dia-a-dia do pedagogo no espaço da escola; 34) Normas Técnicas para Trabalhos acadêmicos; 35) Ensinar a pensar: mediações entre o texto, contexto, professor e aluno; 36) Neuroepistemologia: aplicações na Educação; 37) Robótica no ensino fundamental; 38) Fé e razão IV: a ética protestante e o espirito capitalista; 39) Fontes visuais na História; 40) O Livro didático e a prática do professor; 41) História Social: crianças e família; 42) Critérios de Avaliação; 43) Quadrinhos na sala de aula; 44) Uso de conceitos na História; 45) Amazônia; 46) Cidades educadoras: caminhando pela cidade e compreendendo as transformações no tempo e no espaço; 47) Orientações espaciais nos anos inicias; 48) Cultura material e imaterial; 49) Ensino de História Antiga em Sala de Aula; 50) A importância da coleta seletiva no contexto das cidades educadoras; 51) Filosofia da Educação. Essas temáticas criteriosamente escolhidas pelos colegiados dos cursos de Licenciatura nos quais essas práticas formativas interdisciplinares são ofertadas visam atender às demandas da formação docente na atualidade em consonância com os requisitos legais e normativos e os princípios pedagógicos norteadores da instituição analisados anteriormente.

\section{RESULTADOS - PRÁTICAS FORMATIVAS INTERDISCIPLINARES: PERTENCIMENTO E PERMANÊNCIA NA EAD}


De acordo com o Censo da Associação Brasileira de Educação a Distância (ABED, 2016), a área de Ciências Humanas encontra-se em segundo lugar em número de cursos regulamentados e totalmente a distância, com um total 324 cursos. Em relação a todos os cursos de graduação observa-se que em 2016, 34.366 cursos na modalidade presencial e a distância foram ofertados em 2.407 instituições de educação superior no Brasil. Embora se observe um crescimento de matrículas, a permanência tem se constituído em grande desafio. Nesse sentido, não basta apenas possibilitar o acesso, mas é preciso promover a permanência e a conclusão dos cursos por parte dos estudantes. Observa-se que o número de matrículas na modalidade a distância continua crescendo. Esse número atingiu quase 1,5 milhão em 2016, o que representa uma participação de $18,6 \%$ do total de matrículas da educação superior brasileira (BRASIL, 2016).

Conforme Gisi e Gurgel (2016, p. 34) quando os estudantes que conseguem ingressar na educação superior não permanecem e não concluem com sucesso o curso escolhido, é preciso repensar a educação superior, suas políticas, a organização, a gestão e o processo pedagógico das instituições de educação superior. Um dos fatores que dificulta a conclusão do curso na educação superior pode estar relacionado com a falta de aproximação prática com o desenvolvimento de sua profissão e a dificuldade da EAD fazer com que o estudante tenha o sentimento de pertença ao seu Curso.

Assim, a oferta das práticas formativas interdisciplinares para os Cursos de Licenciaturas constitui um elemento fundamental para que os alunos se identifiquem com a profissão e possam ao mesmo tempo verificar e aplicar os conhecimentos que são próprios do seu campo de atuação. O fato de contar com temáticas cujo foco é a atuação docente colabora de maneira essencial para que o estudante perceba a utilidade e sobretudo, a indissolubilidade entre teoria e prática na formação doente, e ainda, a relevância social e científica dos conteúdos que está aprendendo no decorrer de seu curso.

Ao analisar a realização das atividades observou-se que com a oferta dessas práticas formativas os Cursos, além de proporcionar aos cursos o atendimento daquilo que recomendam os instrumentos legais também favorecem o desenvolvimento de sentimento de pertencimento ao curso e à Instituição de Ensino Superior, o que é fundamental para garantir a permanência do estudante até a conclusão do curso.

\section{CONSIDERAÇÕES FINAIS}

Este trabalho apresentou um relato de experiência sobre a oferta de Práticas formativas 
interdisciplinares para cursos de Licenciatura na modalidade a distância de uma Instituição de Ensino privada, cuja sede encontra-se no sul do Brasil. Analisou-se a pertinência da oferta de práticas formativas interdisciplinares na perspectiva da permanência e do pertencimento em curso superior de Licenciatura na modalidade EAD. Os resultados apontaram, que a oferta de práticas formativas interdisciplinares em cursos superiores de Licenciatura na modalidade a distância, em razão de proporcionarem aos estudantes momentos experimentação e aplicação dos conhecimentos adquiridos ao longo do curso, favorecem o desenvolvimento do sentimento de pertencimento no curso colaborando para permanência do estudante no acesso superior.

Espera-se que este relato e os resultados aqui apresentados possam colaborar para 0 desenvolvimento de novas pesquisas que tenham como foco a oferta de práticas formativas em cursos superiores de Licenciatura, bem como, estudos que investiguem a questão do sentimento de pertença ao curso e à instituição por parte do estudante, e sua relação com a permanência na Educação Superior a Distância, tendo em vista à conclusão do curso que realiza.

\section{REFERÊNCIAS}

ABED. Censo EAD Brasil 2016. Disponível em: $<$ http://abed.org.br/censoead2016/Censo_EAD_2016_portugues.pdf.> Acesso em 3 nov. 2017.

BRASIL. Ministério da Educação. INEP - Instituto Nacional de Estudos e Pesquisas Educacionais Anísio Teixeira. Censo da Educação Superior 2016. Disponível em: $<$ http://www.inep.gov.br.>Acessado em 10 de nov. 2017.

BRASIL. Ministério da Educação. Instrumento de avaliação de Cursos de Graduação presencial e a distância. Disponível em: $<$ http://download.inep.gov.br/educacao_superior/avaliacao_cursos_graduacao/instrum entos/2012/instrumento_com_alteracoes_maio_12.pdf.> Acessado em 8 de maio de 2015.

BRASIL. Ministério da Educação. Diretrizes Curriculares Nacionais Gerais da Educação Básica / Ministério da Educação. Secretaria de Educação Básica. Diretoria de Currículos e Educação Integral. Brasília: MEC, SEB, DICEI, 2013. Disponível em: $<$ http://portal.mec.gov.br/docman/julho-2013-pdf/13677-diretrizes-educacaobasica-2013-pdf/file> Acessado em 16 de abril de 2018. 
BRASIL. CNE. Parecer CNE-CP no 02, de 09 de junho de 2015. Institui Diretrizes Curriculares Nacionais para a Formação Inicial e Continuada dos Profissionais do Magistério da Educação Básica. Brasília: Conselho Nacional de Educação, 09 de junho de 2015.

GISI, Maria Lourdes, PEGORINI, Diana Gurgel. As políticas de acesso e permanência na educação superior: a busca da igualdade de resultados. Rev. on line de Política e Gestão Educacional, Araraquara, SP, v. 20, n.1, jan-abr., 2016.

MARTINS, Rosa Elisabete Militz Wypyczynski; Dias, Julice; MARTINS FILHO, Lourival José . O contexto do ensino, pesquisa e extensão na formação docente na Faculdade de Educação da Universidade do Estado de Santa Catarina. Rev. educ. PUC-Camp., Campinas, 21(2):243-254, maio/ago., 2016.

NAKAYAMA.Bárbara Cristina Moreira Sicardi. Práticas Formativas e Desenvolvimento Profissional Docente em Grupos que integram Ensino, Pesquisa e Extensão. EDUCERE - XIII Congresso Nacional de Educação. Curitiba: Pontifícia Universidade Católica do Paraná, 2017. Disponível em: $<$ http://educere.bruc.com.br/arquivo/pdf2017/25753_13086.pdf > Acessado em: $17 / 04 / 2018$. 